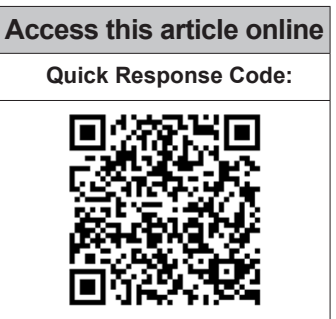

Website:

www.jlponline.org

DOI:

10.4103/JLP.JLP_154_17
Department of Pathology and Transfusion

Medicine, Santokba

Durlabhji Hospital, Jaipur, Rajasthan, India

Address for correspondence:

Dr. Rateesh Sareen, Department of Pathology and Transfusion

Medicine, Santokba

Durlabhji Hospital, Jaipur, Rajasthan, India. E-mail: drrateeshsareen@ yahoo.co.in

Submission: $14-11-2017$ Accepted: 25-05-2018

\title{
Incubation and its effect on Leishman stain
}

\author{
Rateesh Sareen, Menka Kapil, GN Gupta
}

\section{Abstract:}

BACKGROUND: Leishman stain is the universal stain used in staining of peripheral blood smears all over the world.

AIM: To study the effect of incubation of buffer solution, slide alone and slide \& buffer both on standard Leishman staining. The staining at times causes difficulty particularly in rainy season when there is increased moisture.

METHOD: The study comprised of twenty peripheral blood smears selected consecutively in batches of ten each for two successive days. Minor modification in standard Leishman stain was done by either incubating slide or buffer solution or both. The staining characteristics were scored using system by NG et al and the statistical analysis was done.

RESULTS: The highest mean score for background (1.5), nuclear (1.55), cytoplasmic features (1.5) and granules visualization (1.8) were seen in technique involving incubation of both slide and buffer. The results were statistically significant.

CONCLUSION: We found that incubating glass slides or buffer solution or both yield better stained slide. Our study showed that there was better staining features seen in incubated slide verses routine method.

Key words:

Incubation, Leishman stain, moisture

\section{Introduction}

T eishman stain is named after Scottish $\perp$ pathologist Sir William Boog Leishman. William Borg Leishman and Karl Reuter independently discovered the stain in 1901 which was a practical modification of Malachowski's stain. ${ }^{[1]}$ They adopted the best aspects of the stains developed by Malachowski and Jenner, i.e., they used both polychromed methylene blue (accidentally done by Romanowsky who got the name, systematically done by Ernst Malachowski even before Romanowsky, and rediscovered by Bernhard Nocht, but unknown to Jenner, May, Grunwald and many others who used simple methylene blue) and filtering the Azure Eosinate precipitate from the aqueous mixture and redissolving in an alcoholic

This is an open access journal, and articles are distributed under the terms of the Creative Commons Attribution-NonCommercial-ShareAlike 4.0 License, which allows others to remix, tweak, and build upon the work non-commercially, as long as appropriate credit is given and the new creations are licensed under the identical terms.

For reprints contact: reprints@medknow.com solvent (Jenner's wisdom). However, there were subtle differences between Leishman's and Reuter's methods. Leishman used methanol (like Jenner) and substituted Eosin B for Eosin Y, whereas Reuter used ethyl alcohol and rightly stressed the importance of using an absolutely pure solvent. Both methods produced a stable stain and the desired purple color.

Leishman stain generally shows violet color of the nucleus and neutrophil granules, making the differential count convenient due to better contrast between nucleus and cytoplasm. The contrast depends on two components Azure B and Eosin Y. Azure $B$ is one of the products from oxidation of methylene blue. Azure B and Eosin Y are advocated by International Committee for Standardization in Hematology. ${ }^{[2]}$ It is cheap, easily available, and like other Romanowsky stain imparts good contrast

How to cite this article: Sareen R, Kapil M, Gupta GN. Incubation and its effect on Leishman stain. J Lab Physicians 2018;10:357-61. 


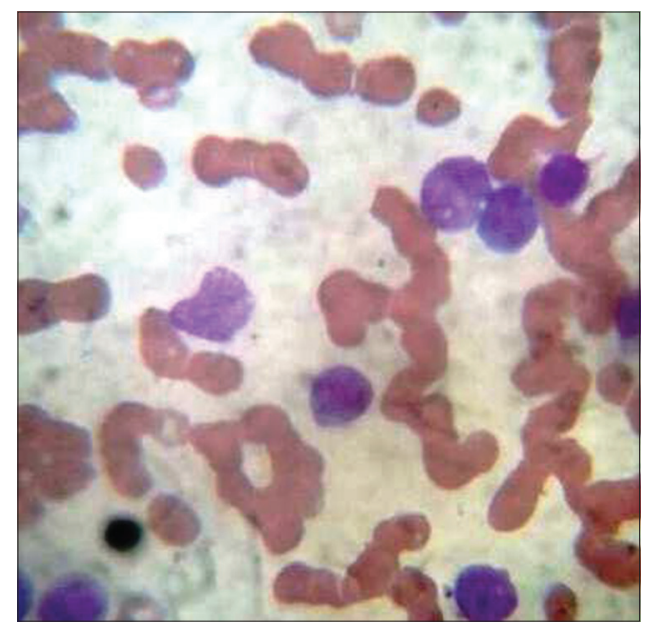

Figure 1: Leishman stain blood smear routine ( $\times 100$ oil immersion) - routine Leishman staining

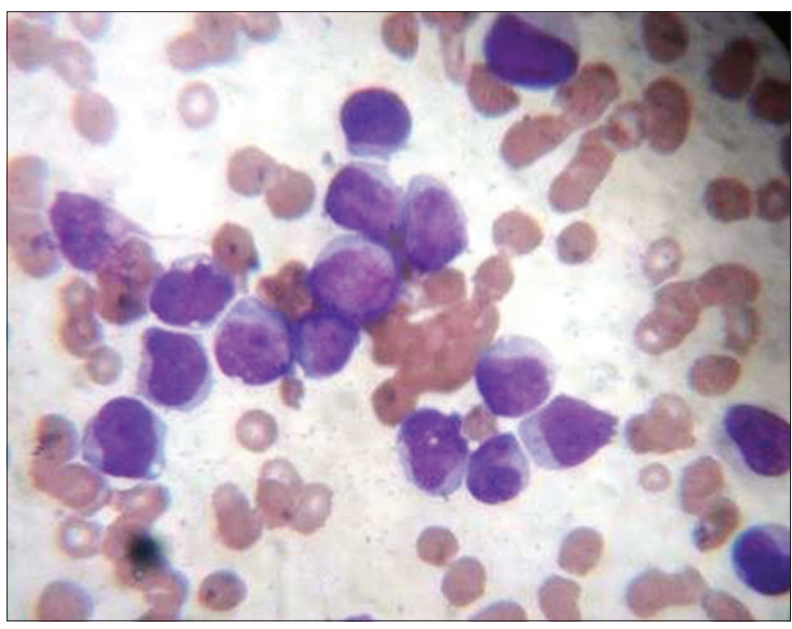

Figure 3: Leishman stain blood smear routine ( $\times 100$ oil immersion) - incubated glass slide and incubated buffer

differentiation, making it a fairly acceptable stain to hematologists worldwide. Romanowsky stain is composed of combinations of acid and basic dyes and universally employed for staining blood films.

The uses of automated analyzers have greatly reduced the peripheral blood smear preparation workload on laboratories. The blood smear examination is still required in the diagnosis based on the morphological assessment of cells such as blasts in case of leukemia, parasites such as malaria, hemolytic anemia for fragmented red blood cell (RBC), schistocytes, helmet cells, cytoplasmic granules, and many more. The art of peripheral blood smear preparation, staining, and examination is losing its shine. In such a scenario, troubleshooting for suboptimal staining becomes challenging. The interference of moisture in Leishman stain is a well-known problem in tropical climate and in rainy season, even in most well-equipped laboratories. The present study aims at comparing the effect of

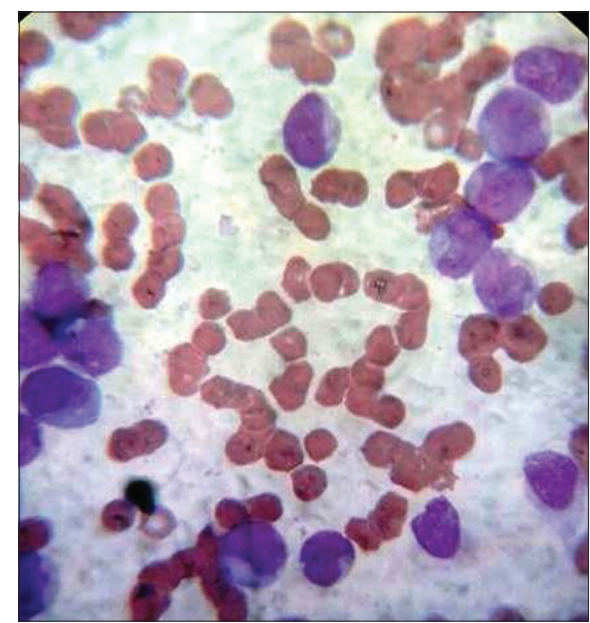

Figure 2: Leishman stain blood smear routine ( $\times 100$ oil immersion) - incubated slide

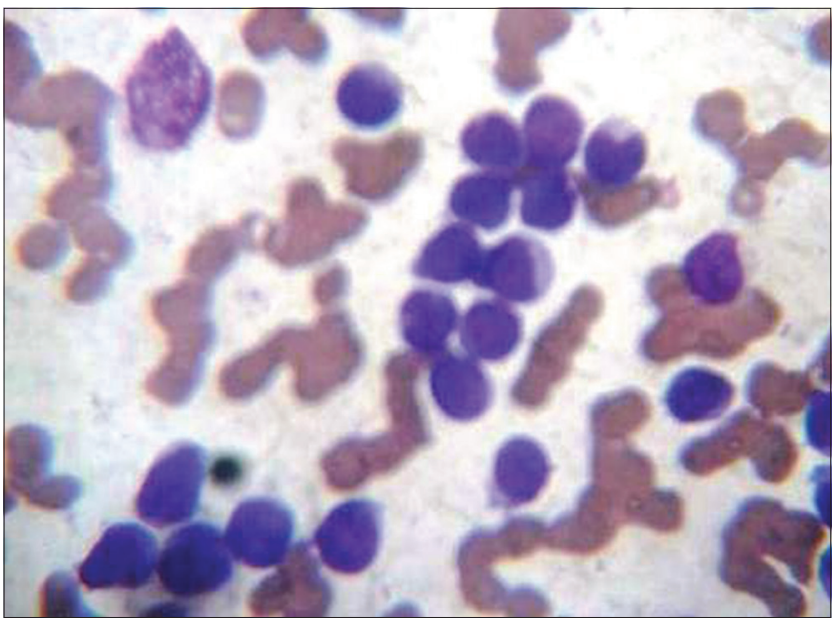

Figure 4: Leishman stain blood smear routine (×100 oil immersion) - incubated buffer

incubation (heat) on quality of Leishman-stained peripheral blood smear to circumvent the problems encountered by under-resourced laboratories.

\section{Materials and Methods}

We conducted a prospective in the Department of Pathology and Transfusion Medicine, in a tertiary care hospital in Western India over a period of 5 days in August month, postmonsoon period. Twenty consecutive samples from patients for peripheral blood examination were taken successively for 2 days in afternoon. The selection of patients was random. The timing of cases was decided in the afternoon so that the extra workload of staining does not compromise with routine workflow and routine turnaround time. The study was approved by IEC(Institutional Ethics Committee).

\section{Inclusion criteria}

Inclusion criteria were all twenty consecutive samples irrespective of age, sex, and cell count. 


\section{Exclusion criteria}

Hemolysed sample.

The routine everyday control slide was taken as control for assessing the staining characteristics. Twenty samples from different patients were collected in ethylenediaminetetraacetic acid vials. A total of four peripheral blood smears were prepared from each collected sample. The smears were stained by four different techniques as under:

1. Routine Leishman staining procedure (RS) [Figure 1]

2. Routine Leishman staining using incubated glass slides $\left(37^{\circ} \mathrm{C}\right.$ for an hour) (IS) [Figure 2]

3. Routine Leishman staining using incubated buffer (IB) solution $\left(37^{\circ} \mathrm{C}\right.$ for an hour) (IB) [Figure 3]

4. Routine Leishman staining using incubated glass slides and IB solution $\left(37^{\circ} \mathrm{C}\right.$ for $4 \mathrm{~h}$ ) (ISB) [Figure 4].

The standard procedure involves placing six or eight drops of stain on unfixed films, leaving for 15-20 s, not longer, and then adding double the quantity, i.e., $12-16$ drops of distilled water $(\mathrm{pH}-6.8)$. It is followed by thorough mixing and keeping the slide undisturbed for 15-20 min on the flat top. The slide is then washed with gentle stream of distilled water followed by drying and examination. The smears were scored for quality of staining as per scoring system by $\mathrm{Ng}$ et al. after few modifications by two pathologists independently. ${ }^{[3]}$ Each one of them scored the slide in terms of morphological characteristics. Two independent pathologists were given slides in a manner that they were unaware of the technique of staining in each of the four slides, and the pathologist was also unaware of the scoring done by another pathologist. The scores were then collected from the two pathologists and the average was taken. The smears were examined for primarily four features - nucleus, cytoplasmic features, granules, and background. The smears were given a score from 0 - poor, 1 - satisfactory, and 2 - excellent for each of the four features. Thus, each smear could get a highest score of 8 or minimum score 0 . The results were recorded and statistical analysis was done by online free statistical software using SAS. The images were captured using digital camera fixed to microscope. The images as shown in Figures 1-4 are without any modification in terms of color, Hue, brightness, and contrast.

\section{Results}

Out of 20 patients, 15 (75\%) were male and 5 (25\%) female. The mean age of the study population was 45 years. Total scores for background for IS were 17,
Table 1: Comparative score of morphological features of different staining techniques

\begin{tabular}{|c|c|c|c|c|}
\hline & $\begin{array}{c}\text { Score } \\
0(\%)\end{array}$ & $\begin{array}{l}\text { Score } \\
1(\%)\end{array}$ & $\begin{array}{l}\text { Score } \\
2(\%)\end{array}$ & $\begin{array}{l}\text { Total } \\
\text { score }\end{array}$ \\
\hline \multicolumn{5}{|c|}{ Background features } \\
\hline RS & $12(60)$ & $8(40)$ & 0 & 8 \\
\hline IS & $6(30)$ & $11(55)$ & $3(15)$ & 17 \\
\hline IB & $9(45)$ & $9(45)$ & $2(10)$ & 13 \\
\hline ISB & 0 & $10(50)$ & $10(50)$ & 20 \\
\hline \multicolumn{5}{|c|}{ Nuclear features } \\
\hline RS & $1(5)$ & $19(95)$ & 0 & 19 \\
\hline IS & $1(5)$ & $18(90)$ & $1(5)$ & 20 \\
\hline IB & $1(5)$ & $18(90)$ & $1(5)$ & 20 \\
\hline ISB & 0 & $9(45)$ & $11(55)$ & 31 \\
\hline \multicolumn{5}{|c|}{ Cytoplasmic features } \\
\hline RS & $13(65)$ & $7(35)$ & 0 & 7 \\
\hline IS & $7(35)$ & $12(60)$ & $1(5)$ & 14 \\
\hline IB & $10(50)$ & $9(45)$ & $1(5)$ & 11 \\
\hline ISB & 0 & $10(50)$ & $10(50)$ & 30 \\
\hline \multicolumn{5}{|c|}{ Granules and others } \\
\hline RS & $9(45)$ & $11(55)$ & 0 & 11 \\
\hline IS & $5(25)$ & $15(75)$ & 0 & 15 \\
\hline IB & $3(15)$ & $14(70)$ & $3(15)$ & 20 \\
\hline ISB & 0 & $4(20)$ & $16(80)$ & 36 \\
\hline
\end{tabular}

RS = Routine Leishman staining, IS = Incubated slide, IB = Incubated buffer, ISB = Incubated buffer solution

Table 2: Statistical calculations for smear quality using ANOVA

\begin{tabular}{|c|c|c|c|c|}
\hline & RS & IS & IB & ISB \\
\hline \multicolumn{5}{|l|}{ Background } \\
\hline Total score & 8 & 17 & 13 & 20 \\
\hline Mean & 0.4 & 0.85 & 0.65 & 1.5 \\
\hline SD & 0.5026 & 0.6708 & 0.6078 & 0.513 \\
\hline \multicolumn{5}{|c|}{ Nuclear features } \\
\hline Total score & 19 & 20 & 20 & 31 \\
\hline Mean & 0.95 & 1 & 1 & 1.55 \\
\hline $\mathrm{SD}$ & 0.2236 & 0.3244 & 0.3244 & 0.5104 \\
\hline \multicolumn{5}{|c|}{ Cytoplasmic features } \\
\hline Total score & 7 & 14 & 11 & 30 \\
\hline Mean & 0.35 & 0.7 & 0.55 & 1.5 \\
\hline SD & 0.4894 & 0.5712 & 0.6048 & 0.513 \\
\hline \multicolumn{5}{|c|}{ Granules and others } \\
\hline Total score & 11 & 15 & 20 & 36 \\
\hline Mean & 0.55 & 0.75 & 1 & 1.8 \\
\hline SD & 0.5104 & 0.443 & 0.562 & 0.4104 \\
\hline
\end{tabular}

$\mathrm{SD}=$ Standard deviation, RS = Routine Leishman staining, IS = Incubated slide, IB = Incubated buffer, ISB = Incubated buffer solution

IB 13, and ISB 20. Nuclear scores were best scored in ISB 31 and IS and IB 20. The cytoplasmic features were scored 30 for ISB, 14 for IS, and 11 for IB. The granules were scored as 36 for ISB, 20 for IB, and 15 for IB [Table 1]. The mean scores for three modifications were 1.5 for ISB, 0.85 for IS, and 0.65 for IB [Table 2]. The routine method had a mean score of 0.4 . The $f$ value was 12.5254 , and the results were significant for $P<0.001$. 


\section{Discussion}

Peripheral blood examination is the most useful test done in hematology for evaluation of anemia, assessment of thrombocytopenia, identification of morphologically abnormal cells in diagnosis of leukemia, and detection of parasites. The simplicity of test makes it accessible to several people skilled or less skilled. Each laboratory should formulate standard operating procedure for blood film staining and examination so that artifacts such as distorted RBC, holes, or too thin tail are kept to be minimum. A suboptimal staining leads to loss of RBC morphology details and polychromasia. Poor staining of blood film affects identification of vital clues from peripheral smear examination like spherocytosis , rouleaux formation etc.

Leishman stain is unsurpassed in the world for staining of blood cells for differential leucocyte analysis. The seminal paper by Leishman in $1901^{[4]}$ elaborately described the procedure that we still follow after 100 years with minor modifications. ${ }^{[5,6]}$

There are certain points one should remember while performing Leishman stain ${ }^{[5,7]}$ such as avoid pipetting from the stock solution to minimize exposure to moisture that can spoil Leishman stain. Size of blood drop, angle, speed, and pressure of spreader while preparing smear need to be uniform. Insufficient washing, old reagent, staining time in excess ( $>20 \mathrm{~min})$, and alkaline $\mathrm{PH}$ of buffer $>7.0$ may cause excessive bluing of smears and need to be checked regularly. Excessive acidic $\mathrm{pH}$ or reduced staining time causes excessive pinkish discoloration of smear, while excessive basic $\mathrm{pH}$ and/or increased staining time causes bluish discoloration. One needs to be aware of the above-mentioned effects for obtaining optimal staining.

The best morphological features were seen in smears which were stained by incubated glass slide and IB technique [Table 1]. Highest scores for background were obtained in ISB technique followed by IS and IB. The nuclear features were best seen in ISB followed by IS and IB technique. The cytoplasmic features were crisp in ISB followed by IS and IB technique. Granules were appreciated clearly in ISB followed by IB and IS.

One-way ANOVA analysis was done using online free statistical calculator [Table 2]. The results of statistical analysis showed a higher $f$ value12.5254 when comparing the three modified Leishman staining procedures. A high $F$ value rejects the null hypothesis; in our case, there was a positive effect of incubation on the quality of Leishman stain whether its slide or buffer or both incubated under controlled conditions.
It is worth mentioning that there was no issue with fixation of blood smears. One plausible cause for improved staining can be the reduced moisture, although the staining was performed in controlled environment with air-conditioned room. We did not use a fresh Leishman stock solution, rather we used the same bottle which was used to stain routine cases in laboratory.

The best staining characteristics were obtained in combo incubation technique (ISB); however, it is cumbersome. The second best technique in our study was IS followed by IB. In nutshell, incubation of buffer or glass slide or both improved the staining qualities of blood smear.

The study provides statistically proven improvement in staining characteristics of Leishman-stained blood smear. Since our study had limited number of patients, the findings of this study need to be verified on large population studies.

It has been observed that in the rainy season, the Leishman staining is suboptimal many times. Our study could be pretty useful for those who face the problem with staining in tropics as incubation of slides or buffer or both could circumvent the problem. A literature search could not reveal any significant work.

\section{Conclusion}

Our study has demonstrated improved staining characteristics in Leishman-stained peripheral blood smears by slide incubation at $37^{\circ}$ centigrade. We have shared our experience for modification of Leishman stain which was quite useful in the rainy season in tropical climate. More studies are required to validate our findings and the cause behind the observation.

\section{Financial support and sponsorship} Nil.

\section{Conflicts of interest}

There are no conflicts of interest.

\section{References}

1. Krafts KP, Hempelmann E, Oleksyn BJ. The color purple: From royalty to laboratory, with apologies to malachowski. Biotech Histochem 2011;86:7-35.

2. ICSH reference method for staining of blood and bone marrow films by Azure B, Eosin Y (Romanowsky stain). Br J Haematol 1984;57:70771. http:/ / onlinelibrary.wiley.com/doi/10.1111/j.1365-2141.1984. tb02949.x/pdf. [Last accessed on 2018 Mar 31].

3. Ng WF, Choi FB, Cheung LL, Wu C, Leung CF, Ng CS, et al. Rehydration of air-dried smears with normal saline. Application in fluid cytology. Acta Cytol 1994;38:56-64. 
4. Leishman WB. Note on a simple and rapid method of producing Romanowsky staining in malarial and other blood films. Br Med J 1901;2:757-8.

5. Shute PG, Maryon M. An Improved Method of Preparing Romanowsky Stains (with some hints on staining); 1965. Available from: http://www.whqlibdoc.who.int/malaria/ WHO_Mal_478.64.pdf. [Last accessed on 2018 Mar 21].
6. Bain BJ, Lewis SM. Preparation and staining methods for blood and bone marrow films. In: Barbara JB, Imelda B, Michael AL, Lewis SM, editors. Dacie and Lewis Practical Hematology. $11^{\text {th }} \mathrm{ed}$. New York: Churchill Livingstone; 2011.

7. Fasakin KA, Okogun GR, Omisakin CT, Adeyemi AA, Esan AJ. Modified Leishman stain: The mystery unfolds. Br J Med Med Res 2014;4:4591-606. 